\title{
PERSEPSI ANGGOTA TERHADAP UNIT USAHA SUSU KOPERASI UNIT DESA (KUD) CEPOGO KECAMATAN CEPOGO KABUPATEN BOYOLALI
}

\author{
Ziva Arsiatul Isna ${ }^{1}$, Sugihardjo ${ }^{2}$, Eny Lestari ${ }^{2}$ \\ ${ }^{1}$ Program Studi Penyuluhan dan Komunikasi Pertanian Universitas Sebelas Maret \\ ${ }^{2}$ Departemen Soial Ekonomi, Fakultas Pertanian, Universitas Sebelas Maret
}

\begin{abstract}
Abstrak
Kabupaten Boyolali merupakan pusat populasi sapi perah tertinggi di Jawa Tengah. Wilayah yang memiliki populasi sapi perah berada di Kecamatan Cepogo. Berdasarkan mutasi anggota KUD Cepogo tidak semua anggota KUD aktif dalam unit usaha susu. Penelitian ini bertujuan untuk menganalisis persepsi anggota terhadap unit usaha susu KUD Cepogo, menganalisis faktor-faktor pembentuk persepsi terhadap unit usaha susu KUD Cepogo, dan menganalisis pengaruh antara faktor-faktor pembentuk persepsi terhadap unit usaha susu KUD Cepogo. Analisis data menggunakan Regresi Linear Berganda. Hasil penelitian menunjukkan bahwa $67 \%$ anggota memiliki persepsi yang baik terhadap unit usaha KUD Cepogo. Faktor-faktor pembentuk persepsi anggota terhadap unit usaha susu KUD Cepogo meliputi: pendidikan formal, pendidikan non formal, pengalaman, pendapatan, dan motivasi. Faktor-faktor pembentuk persepsi secara simultan berpengaruh signifikan terhadap persepsi anggota unit usaha susu KUD Cepogo. Secara parsial variabel pengalaman, pendapatan, dan motivasi berpengaruh signifikan terhadap persepsi anggota, sedangkan variabel pendidikan formal dan pendidikan non formal tidak berpengaruh signifikan terhadap persepsi anggota terhadap unit usaha susu KUD Cepogo.
\end{abstract}

Kata kunci: Unit Usaha Susu, KUD Cepogo, Persepsi

\begin{abstract}
Boyolali Regency is the highest dairy population center in Central Java. The area that has a dairy population is in Cepogo Subdistrict. Based on cepogo kud member mutation, not all kud members are active in milk business unit. This study aims to analyze the perception of members of the cepogo kud milk business unit, analyze the factors that shape the perception of the cepogo kud milk business unit, and analyze the influence between the factors that shape the perception of the cepogo kud milk business unit. Data analysis using Multiple Linear Regression. The results showed that $67 \%$ of members have a good perception of cepogo kud business unit. Factors that shape members' perception of Cepogo's dairy business unit include: formal education, non-formal education, experience, income, and motivation. The perception-forming factors simultaneously have a significant effect on the perception of members of the Cepogo KUD dairy business unit. Partial variables of experience, income, and motivation have a significant effect on members' perceptions, while the variables of formal education and non-formal education have no significant effect on members' perception of cepogo's dairy business unit.
\end{abstract}

Keywords: Dairy Business Unit, Kud Cepogo, Perception 


\section{Pendahuluan}

Menurut UU RI No. 25 Tahun 1992 tentang perkoperasian memberikan definisi koperasi Indonesia sebagai badan usaha yang beranggotakan orang seorang atau badan hukum koperasi dengan melandaskan kegiatannya berdasarkan prinsip koperasi sekaligus sebagai gerakan ekonomi rakyat yang berdasarkan atas asas kekeluargaan. Salah satu jenis Koperasi yang berperan penting untuk mensejahterakan masyarakat adalah Koperasi Unit Desa (KUD). Koperasi Unit Desa (KUD) adalah suatu Koperasi serba usaha yang beranggotakan penduduk desa dan berlokasi didaerah pedesaan, daerah kerjanya mencakup satu wilayah kecamatan. Pembentukan KUD menurut Nadhiroh (2019) bertujuan; menjamin terlaksananya program peningkatan produksi pertanian, peternakan khususnya produksi pangan secara efektif dan efisien; memberikan kepastian bagi para petani produsen khusunya serta masyarakat desa pada umumnya, bahwa mereka tidak hanya mempunyai tanggung jawab untuk ikut serta meningkatkan produksi sendiri, tetapi juga secara nyata dapat memetik dan menikmati hasilnya guna meningkatkan taraf hidup serta kesejahteraannya.

Kabupaten Boyolali merupakan pusat populasi sapi perah di Provinsi Jawa Tengah (Badan Pusat Statistik, 2019). Kabupaten Boyolali terdiri dari 19 kecamatan, namun populasi sapi perah hanya tersebar di beberapa kecamatan saja. Wilayah yang memiliki potensi populasi sapi perah terdapat di Kecamatan Cepogo dengan jumlah 18.173 ekor sapi perah. Adanya jumlah populasi sapi perah di Kecamatan Cepogo, pemerintah Kabupaten Boyolali membentuk lembaga yang disebut Koperasi Unit Desa yang didalamnya terdapat unit usaha susu. Unit usaha susu di KUD tidak hanya melayani pemasaran hasil produksi susu sapi perah, tetapi juga melayani pembinaan kepada peternak, dan fasilitas-fasilitas penunjang kualitas susu sapi perah. Hal tersebut sejalan dengan pendapat Santosa (2018) terdapat 2 peran unit usaha di KUD, yaitu peran langsung dan tidak langsung. Peran langsung meliputi kegiatan pengkreditan, penyediaan dan penyaluran sarana produksi, pengolahan dan pemasaran hasil produksi, pengangkutan dan perdagangan. Peran tidak langsung meliputi membangun dan mengembangkan potensi dan kemampuan ekonomi anggota, meningkatkan kesejahteraan ekonomi dan sosial, mempertinggi kualitas hidup, mengurangi pengangguran dan kemiskinan, dan mengurangi urbanisasi.

Berdasarkan mutasi anggota KUD Cepogo tahun 2019 sebanyak 838 anggota yang aktif dalam unit usaha susu dengan jumlah total anggota 5.745. Artinya tidak semua anggota KUD aktif dalam unit usaha susu, untuk itu perlu dikaji bagaimana sebenarnya persepsi anggota terhadap unit usaha susu KUD Cepogo. Maka dari itu peneliti tertarik untuk meneliti tentang persepsi anggota terhadap unit usaha susu KUD Cepogo. Persepsi anggota yang akan dikaji dalam penelitian ini adalah terkait kesan-kesan penilaian menurut anggota terhadap unit usaha susu KUD.

Rumusan masalah dalam penelitian ini meliuti bagaimana apa saja faktor-faktor pembentuk persepsi terhadap unit usaha susu KUD Cepogo, persepsi anggota terhadap unit usaha susu KUD Cepogo, dan bagaimana pengaruh antara faktor-faktor pembentuk persepsi terhadap unit usaha susu KUD Cepogo. Tujuan dari penelitian ini adalah menganalisis faktor-faktor pembentuk persepsi terhadap unit usaha susu KUD Cepogo, menganalisis persepsi anggota terhadap unit usaha susu KUD Cepogo, menganalisi pengaruh antara faktor-faktor pembentuk persepsi terhadap unit usaha susu KUD Cepogo. Walgito (2010) bahwa dalam persepsi sekalipun stimulusnya sama, tetapi karena pengalaman tidak sama, kemampun berpikir tidak sama, kerangka acuan tidak sama, adanya kemungkinan hasil persepsi antara individu satu dengan individu yang lain tidak sama. Keadaan tersebut menggambarkan bahwa persepsi memang bersifat individual. Penelitian terdahulu yang menjadi dasar penelitian dari Anis Nur Aini (2015) tentang Pengaruh Keanggotaan Koperasi Terhadap Pendapatan Peternak Sapi Perah di Kud Cepogo, Kecamatan Cepogo, Kabupaten Boyolali. Zamzam (2016) tentang Persepsi Masyarakat terhadap Keberadaan Koperasi Mekar Sari dalam Meningkatkan Kesejahteraan 
Anggotanya.Bagian ini berisi latar belakang penelitian, perumusan/identifikasi masalah berdasarkan tinjauan ilmiah, tujuan penelitian/penulisan manuskrip. Teori dan rujukan penelitian sebelumnya yang menjadi dasar penelitian ini ditulis dalam bentuk paragraf.

\section{Metode Penelitian}

Persepsi dipengaruhi oleh faktor pembentuk atau karakteristik individu, hasil persepsi antar individu akan berbeda sekalipun obyeknya sama. Faktor pembentuk persepsi dalam penelitian meliputi pendidikan formal $\left(\mathrm{X}_{1}\right)$, pendidikan non formal $\left(\mathrm{X}_{2}\right)$, pengalaman $\left(\mathrm{X}_{3}\right)$, pendapatan $\left(\mathrm{X}_{4}\right)$, dan motivasi $\left(\mathrm{X}_{5}\right)$ diduga memiliki pengaruh terhadap persepsi anggota terhadap unit usaha susu Koperasi Unit Desa (KUD) Cepogo Kecamatan Cepogo Kabupaten Boyolali. Metode dasar yang digunakan dalam penelitian ini adalah kuantitatif dengan teknik survei. Pemilihan lokasi penelitian dilakukan dengan cara purposive. Pengambilan sampel dalam penelitian ini dilakukan dengan menggunakan metode cluster random sampling yaitu sebanyak 60 responden dengan pengambilan sampel cara undian. Jenis data yang digunakan adalah kuantitatif dan kualitatif, serta sumber data primer dan sekunder. Teknik pengumpulan data dilakukan dengan cara observasi, wawancara, pencatatan dan dokumentasi. Teknik analisis data yang digunakan pada penelitian ini adalah uji regresi linear berganda. Model Persamaan regresi linier berganda adalah sebagai berikut:

$\mathrm{Y}=\mathrm{b}_{0}+\mathrm{b}_{1} \mathrm{X}_{1}+\mathrm{b}_{2} \mathrm{X}_{2}+\mathrm{b}_{3} \mathrm{X}_{3}+\mathrm{e}$

Keterangan:

Y : Efektivitas Kelompok Tani

$\mathrm{b}_{0} \quad$ : Konstanta

$\mathrm{X}_{1} \quad$ : Faktor Ciri Kelompok

$\mathrm{X}_{2} \quad$ : Faktor Fungsi Tugas

$\mathrm{X}_{3} \quad$ : Faktor Luar Kelompok

$b_{1}-b_{3}$ : Koefisien Regresi

e : Standar error

\section{Hasil dan Pembahasan}

a) Faktor-faktor pembentuk persepsi

1) Pendidikan Formal

Tabel 1

Distribusi Responden berdasarkan Pendidikan Formal

\begin{tabular}{ccc}
\hline Kategori & Jumlah & Persentase $(\%)$ \\
\hline Tidak Sekolah & 4 & 6,7 \\
Tamat SD & 33 & 55,0 \\
Tamat SMP & 7 & 11,7 \\
Tamat SMA & 16 & 26,7 \\
Perguruan Tinggi & 0 & 0,0 \\
\hline Jumlah & 60 & 100,0 \\
\hline
\end{tabular}

Sumber: Analisis Data Primer, (2020)

Berdasarkan tabel 1 menunjukkan bahwa tingkat pendidikan formal responden berada dalam kategori tamat SD dengan jumlah 33 orang (55\%). Berdasarkan kondisi dilapang, bahwa responden hanya tamat SD disebabkan oleh faktor sosial dan ekonomi. 
Perbedaan tingkat pendidikan formal responden berdampak pada persepsinya. Sesuai dengan pendapat Rakhmat (2011) bahwa perbedaan tingkat pendidikan akan menghasilkan perbedaan penilaian pada suatu obyek atau peristiwa.

2) Pendidikan Non Formal

Tabel 2

Distribusi Responden berdasarkan Pendidikan Non-Formal

\begin{tabular}{cccc}
\hline Kategori & Skor & Orang & Persentase (\%) \\
\hline Sangat Rendah & $2,0-3,6$ & 18 & 30,0 \\
Rendah & $3,7-5,3$ & 32 & 53,3 \\
Sedang & $5,4-7,0$ & 9 & 15,0 \\
Tinggi & $7,1-8,7$ & 0 & 0,0 \\
Sangat Tinggi & $8,8-10,4$ & 1 & 1,7 \\
\hline Jumlah & & 60 & 100,0 \\
\hline
\end{tabular}

Sumber: Analisis Data Primer, (2020)

Berdasarkan tabel 2 dapat diketaui bahwa pendidikan non formal yang pernah dilakukan responden berada dalam kategori rendah dengan jumlah 32 orang $(53,3 \%)$ responden. Artinya responden tersebut mengikuti penyuluhan atau pembinaan sebanyak 1 kali pertemuan dalam satu tahun. Kondisi ini disebabkan kegiatan pembinaan atau penyuluhan oleh KUD Cepogo kepada anggotanya tidak menentu, kadang dilakukan dalam tiga bulan sekali atau enam bulan sekali. Responden dalam hal ini juga tidak melakukan pertemuan secara individu terhadap penyuluh.

3) Pengalaman

Tabel 3

Distribusi Responden berdasarkan Pengalaman

\begin{tabular}{cccc}
\hline Kategori & Skor & Orang & Persentase $(\%)$ \\
\hline Sangat Rendah & $2,0-3,6$ & 0 & 0,0 \\
Rendah & $3,7-5,3$ & 0 & 0,0 \\
Sedang & $5,4-7,0$ & 4 & 6,7 \\
Tinggi & $7,1-8,7$ & 6 & 10,0 \\
Sangat Tinggi & $8,8-10,4$ & 50 & 83,3 \\
\hline Jumlah & & 60 & 100,0 \\
\hline
\end{tabular}

Sumber: Analisis Data Primer, (2020)

Berdasarkan tabel 3 menunjukkan bahwa pengalaman responden berada dalam kategori sangat tinggi yaitu sebanyak 50 orang $(83,3 \%)$. Artinya responden melakukan usaha ternak sapi perah dan bergabung menjadi anggota KUD dengan kurun waktu lebih dari 15 tahun. Rata-rata usaha ternak sapi perah di lokasi penelitian merupakan usaha turun temurun, sehingga banyak responden yang telah memiliki pengalaman sejak dini. Aini (2015) semakin lama pengalaman peternak sapi perah, maka pengetahuan dalam beternak akan semakin banyak. Lamanya menjadi anggota KUD Cepogo juga menyebabkan pengalaman semakin bertambah, karena telah melalui rangkaian peristiwa yang pernah dihadapi. 
4) Pendapatan

Tabel 4

Distribusi Responden Berdasarkan Pendapatan

\begin{tabular}{crcc}
\hline Kategori & Pendapatan (per bulan) & Orang & Persentase (\%) \\
\hline Sangat rendah & $<$ Rp. 1.000 .000 & 6 & 10,0 \\
Rendah & Rp.1.000.000-Rp.1.500.000 & 8 & 13,3 \\
Sedang & Rp.1.500.000-Rp.2.500.000 & 15 & 25,0 \\
Tinggi & Rp.2.500.000-Rp.3.500.000 & 20 & 33,3 \\
Sangat tinggi & $>$ Rp.3.500.000 & 11 & 18,4 \\
\hline Jumlah & & 60 & 100,0 \\
\hline
\end{tabular}

Sumber: Analisis Data Primer

Berdasarkan tabel 4 menunjukkan bahwa pendapatan responden termasuk dalam kategori tinggi (Rp. 2.500.000 - Rp. 3.500.000) sebanyak 20 orang (33,3\%). Pendapatan responden dalam kategori tersebut diperoleh dari hasil usahatani, usaha ternak sapi perah, pegawai, dan guru honorer. Mulyana (2004), berpendapat bahwa tingkat penghasilan atau pendapatan seseorang merupakan faktor internal yang mempengaruhi atensi seseorang. Perbedaan pendapatan seseorang akan mempengaruhi tingkat persepsinya terhadap objek.

5) Motivasi

Tabel 5

Distribusi Responden berdasarkan Jumlah Motivasi

\begin{tabular}{cccc}
\hline Kategori & Skor & Orang & Persentase (\%) \\
\hline Sangat Rendah & $8,0-14,4$ & 4 & 6,7 \\
Rendah & $14,5-20,9$ & 12 & 20,0 \\
Sedang & $21,0-27,4$ & 12 & 20,0 \\
Tinggi & $27,5-33,9$ & 19 & 31,7 \\
Sangat Tinggi & $34,0-40,4$ & 13 & 21,7 \\
\hline Jumlah & & 60 & 100,0 \\
\hline
\end{tabular}

Sumber: Analisis Data Primer, (2020)

Berdasarkan tabel 5 menunjukkan bahwa motivasi responden termasuk dalam kategori tinggi $(27,5-33,9)$ sebanyak 19 orang $(31,7 \%)$. Artinya motivasi responden tinggi disebabkan hasil dari penjualan susu ke unit usaha susu KUD Cepogo dapat memenuhi kebutuhan sehari-hari, karena pembayaran selalu dilakukan tepat 10 hari. Responden memiliki kesadaran yang cukup tinggi terhadap kemudahan fasilitas yang diberikan unit usaha susu KUD Cepogo. Alasan tersebutlah yang mendorong responden untuk tetap menjadi anggota KUD Cepogo. Menurut Wahyudi (2008), motivasi merupakan kekuatan penggerak dalam diri seseorang yang memaksanya untuk bertindak, atau dapat diartikan keadaan yang mendorong keinginan untuk melakukan hal tertentu guna mencapai tujuan.

b) Persepsi Anggota terhadap Unit Usaha Susu Koperasi Unit Desa (KUD) Cepogo Kecamatan Cepogo Kabupaten Boyolali 


\section{PERSEPSI ANGGOTA} TERHADAP...

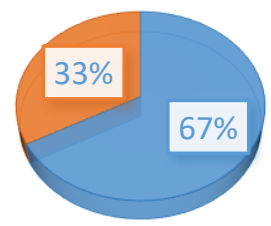

Sumber: Analisis Data Primer, (2020)

Gambar 1

Distribusi Responden Berdasarkan Persepsi Anggota terhadap Unit Usaha Susu Koperasi Unit Desa (KUD) Cepogo

Data diatas menunjukkan distribusi responden berdasarkan persepsi anggota terhadap unit usaha susu KUD Cepogo. Prosentase terbesar persepsi anggota terhadap unit usaha KUD Cepogo termasuk dalam kategori baik yaitu sebanyak 40 orang $(67,0 \%)$. Berdasarkan penjelasan tahap persepsi, dapat disimpulkan bahwa, responden yang persepsinya baik tidak lepas dengan rangsangan informasi dari luar. Informasi tersebut didapat dari pihak lain ataupun berdasarkan rangsangan informasi yang telah dipahami sendiri atau bisa disebut pengalaman pribadi, sehingga persepsi responden menuju ke arah positif. Umumnya responden yang persepsinya baik telah merasakan dampak positif bergabung menjadi anggota KUD Cepogo dan melakukakan penyetoran susu hanya ke KUD Cepogo, karena KUD Cepogo menyediakan fasilitas dan program penunjang untuk meningkatkan produktivitas serta kesejahteraan responden secara tidak langsung. Contohnya adalah program pembinaan atau penyuluhan, sarana produksi, pelayanan kesehatan, simpan pinjam dan lain sebagainya.

c) Pengaruh Faktor-Faktor Pembentuk Persepsi terhadap Persepsi Anggota terhadap Unit Usha Susu Koperasi Unit Desa (KUD) Cepogo Kecamatan Cepogo Kabupaten Boyolali Pengaruh faktor-faktor pembentuk persepsi terhadap persepsi anggota terhadap unit usaha susu KUD Cepogo dianalisis menggunakan regresi linear berganda. Model analisis regresi linear berganda dalam penelitian ini dilakukan dengan pengujian uji asumsi klasik, uji hipotesis, dan uji kelayakan model regresi. Uji asumsi klasik meliputi uji normalitas untuk mengetahui sifat distribusi data penelitian yang berfungsi untuk mengetahui apakah sampel yang diambil normal atau tidak dengan menguji sebaran data yang dianalisis, menggunakan uji Kolmogorof-Smirnov nilai signifikansinya 0,20>0,05 artinya data berdistribusi normal, uji multikolonieritas untuk menguji apakah dalam model regresi ditemukan adanya korelasi antar variabel independen atau tidak dan hasilnya menunjukkan bahwa variabel independen terbebas dari asumsi klasik multikolonieritas karena nilai tolerance $>0,10$ dan nilai VIF $<$ 10, uji heteroskedastisitas untuk menguji apakah dalam model regresi terjadi ketidaksamaan varian dari residual satu pengamatan ke pengamatan lain tetap dan hasilnya semua variabel independen menunjukkan nilai signifikansi lebih dari 0,05 artinya tidak terjadi gejala heteroskedatisitas. Uji hipotesis terdiri dari uji $\mathrm{F}$ untuk mengetahui pengaruh secara simultan dan uji T untuk mengetahui pengaruh secara parsial. Uji kelayakan model regresi atau koefisien determinasi untuk mengetahui seberapa besar kemampuan variabel independen dalam menjelaskan variabel dependen. 
Tabel 6

ANOVA

\begin{tabular}{|c|c|c|}
\hline Model & $\mathrm{F}$ & Sig. \\
\hline Regression & 19,081 & 0,000 \\
\hline Residual & & \\
\hline Total & & \\
\hline
\end{tabular}

Sumber: Analisis Data Primer, (2020)

Berdasarkan tabel 6 hasil uji signifikansi simultan (uji F) menunjukkan bahwa nilai signifikansi sebesar $0,000<0,05$ yang berarti $\mathrm{H}_{0}$ ditolak dan $\mathrm{H}_{1}$ diterima. Secara bersamasama atau simultan menyatakan bahwa variabel independen berpengaruh signifikan terhadap variabel dependen.

Tabel 7

Coefficient

\begin{tabular}{lrr}
\hline \multicolumn{2}{c}{ Unstandardized Coefficients } \\
\hline \multicolumn{1}{c}{ Variabel } & $\mathrm{B}$ & Sig. \\
\hline (Constant) & $-16,748$ & 0,262 \\
Pendidikan Formal $\left(\mathrm{X}_{1}\right)$ & 0,788 & 0,320 \\
Pendidikan Non Formal $\left(\mathrm{X}_{2}\right)$ & $-0,657$ & 0,278 \\
Pengalaman $\left(\mathrm{X}_{3}\right)$ & 2,959 & 0,000 \\
Pendapatan $\left(\mathrm{X}_{4}\right)$ & 3,740 & 0,000 \\
Motivasi $\left(\mathrm{X}_{5}\right)$ & 2,568 & 0,000 \\
\hline
\end{tabular}

Sumber: Analisis Data Primer 2020

Persamaan model regresi pada analisis koefisien regresi linear berganda:

$\mathrm{Y}=-16,748+0,788 \mathrm{X}_{1}+(-0,657) \mathrm{X}_{2}+2,959 \mathrm{X}_{3}+3,740 \mathrm{X}_{4}+2,568 \mathrm{X}_{5}$

Keterangan:

Y : Persepsi Anggota terhadap Unit Usaha Susu KUD Cepogo

$\mathrm{X}_{1}$ : Pendidikan Formal

$\mathrm{X}_{2}$ : Pendidikan Non Formal

$\mathrm{X}_{3}$ : Pengalaman

$\mathrm{X}_{4}$ : Pendapatan

$\mathrm{X}_{5}:$ Motivasi

1) Pengaruh Pendidikan Formal $\left(\mathrm{X}_{1}\right)$ terhadap Persepsi Anggota terhadap Unit Usaha Susu KUD Cepogo

Berdasarkan tabel 7 nilai koefisien regresi sebesar 0,788. Koefisien bernilai positif artinya hubungan variabel pendidikan formal terhadap persepsi anggota berbanding lurus. Artinya semakin tinggi pendidikan formal maka sejalan dengan meningkatnya persepsi anggota terhadap unit usaha susu KUD Cepogo. Hal ini kurang sejalan dengan kondisi dilapang, bahwa pendidikan formal tidak berpengaruh secara signifikan terhadap persepsi anggota terhadap unit usaha susu KUD Cepogo.

Hasil menunjukkan nilai sig pada variabel pendidikan formal $\left(\mathrm{X}_{1}\right)$ sebesar 0,320 sehingga sig. $>\alpha$ atau $0,320>0,05$. Maka $\mathrm{H}_{0}$ diterima dan $\mathrm{H}_{1}$ ditolak. Artinya pendidikan formal secara parsial tidak mempunyai pengaruh yang signifikan terhadap persepsi anggota dengan tingkat kepercayaan 95\%. Tinggi rendahnya pendidikan formal tidak berpengaruh terhadap persepsi anggota terhadap unit usaha susu KUD Cepogo.

Sesuai dengan pernyataan Sutarto (2016) yang menyatakan tinggi rendahnya pendidikan formal responden tidak berhubungan nyata dengan persepsi petani, pengetahuan dan informasi yang diperoleh responden didapatkan melalui kegiatan yang 
bukan berasal dari pendidikan formal, responden memperoleh pengetahuan dari pendidikan nonformal seperti kegiatan penyuluhan atau pengalaman masa lalu.

2) Pengaruh Pendidikan Non Formal $\left(\mathrm{X}_{2}\right)$ terhadap Persepsi Anggota Terhadap Unit Usaha Susu KUD Cepogo

Berdasarkan tabel 7 nilai koefisien sebesar sebesar -0,657. Koefisien bernilai negatif artinya hubungan variabel pendidikan non formal terhadap persepsi anggota terhadap unit usaha susu KUD Cepogo berbanding terbalik. Artinya semakin sering pendidikan non formal dilakukan maka tidak sejalan dengan meningkatnya persepsi anggota terhadap unit usaha susu KUD Cepogo. Secara parsial pendidikan non formal tidak berpengaruh terhadap persepsi anggota terhadap unit usaha susu KUD Cepogo. Hasil menunjukkan nilai sig pada variabel pendidikan non formal $\left(\mathrm{X}_{1}\right)$ sebesar 0,278 sehingga sig. $>\alpha$ atau $0,278>0,05$. Maka $\mathrm{H}_{0}$ diterima dan $\mathrm{H}_{1}$ ditolak. Artinya pendidikan non formal secara parsial tidak mempunyai pengaruh yang signifikan terhadap persepsi anggota dengan tingkat kepercayaan 95\%. Tinggi rendahnya pendidikan non formal tidak berpengaruh terhadap persepsi anggota terhadap unit usaha susu KUD Cepogo.

Variabel pendidikan non formal tidak berpengaruh signifikan pada persepsi anggota, maka semakin tinggi atau tidaknya pendidikan non formal tidak berpengaruh terhadap persepsi anggota terhadap unit usaha susu KUD Cepogo. Hasil penelitian tidak sesuai dengan pernyataan Luthfi (2018) bahwa pengalaman pelatihan atau penyuluhan atau pembinaan yang dimiliki seseorang (peternak) akan mempengaruhi kecepatan dalam mengambil keputusan.

3) Pengaruh Pengalaman $\left(\mathrm{X}_{3}\right)$ Terhadap Persepsi Anggota terhadap Unit Usaha Susu KUD Cepogo

Berdasarkan tabel 7 nilai koefisien regresi sebesar 2,959. Koefisien bernilai positif artinya hubungan variabel pengalaman terhadap persepsi anggota berbanding lurus. Artinya semakin lama pengalaman maka sejalan dengan meningkatnya persepsi anggota terhadap unit usaha susu KUD Cepogo. Hal ini sejalan dengan kondisi lapang, bahwa pengalaman berpengaruh terhadap persepsi anggota. Hasil olah data menunjukkan bahwa nilai sig pada variabel pengalaman $\left(\mathrm{X}_{3}\right)$ sebesar 0,000 sehingga sig. $\leq \alpha$ atau $0,000<0,05$. Maka $\mathrm{H}_{1}$ diterima dan $\mathrm{H}_{0}$ ditolak. Artinya pengalaman secara parsial mempunyai pengaruh yang signifikan terhadap persepsi anggota dengan tingkat kepercayaan $95 \%$. Maka lama atau sebentarnya pengalaman akan berpengaruh terhadap persepsi anggota terhadap unit usaha susu KUD Cepogo.

Berdasarkan hasil tersebut sesuai dengan pernyataan Rakhmat (2011) pengalaman mempengaruhi kecermatan persepsi. Pengalaman tidak selalu lewat proses belajar formal. Pengalaman kita bertambah melalui rangkaian peristiwa yang pernah dihadapi. Semakin banyak pengalaman maka semakin cermat pula seseorang dalam mempersepsikan obyek.

4) Pengaruh Pendapatan $\left(\mathrm{X}_{4}\right)$ terhadap Persepsi Anggota Terhadap Unit Usaha Susu KUD Cepogo

Berdasarkan tabel 7 nilai koefisien regresi sebesar 3,740. Koefisien bernilai postif artinya hubungan variabel pendapatan terhadap persepsi anggota terhadap unit usaha susu KUD Cepogo berbanding lurus. Artinya semakin tinggi pendapatan maka sejalan dengan meningkatnya persepsi anggota terhadap unit usaha susu KUD Cepogo.

Secara parsial pendapatan berpengaruh terhadap persepsi anggota terhadap unit usaha susu KUD Cepogo. Hasil olah data menunjukkan bahwa nilai sig pada variabel 
pendapatan $\left(\mathrm{X}_{4}\right)$ sebesar 0,000 sehingga sig. $\leq \alpha$ atau $0,000<0,05$. Maka $\mathrm{H}_{1}$ diterima dan $\mathrm{H}_{0}$ ditolak. Artinya pendapatan secara parsial mempunyai pengaruh yang signifikan terhadap persepsi anggota dengan tingkat kepercayaan 95\%. Hal ini menunjukkan pendapatan mampu memberikan pengaruh terhadap persepsi anggota terhadap unit usaha susu KUD Cepogo.

Berdasarkan hasil tersebut, pengaruh antara pendapatan dengan persepsi anggota sejalan dengan pernyataan Mulyana (2004) bahwa tingkat pendapatan sebagai faktor internal jelas mempengaruhi persepsi seseorang terhadap suatu realitas. Perbedaan pendapatan seseorang akan mempengaruhi tingkat persepsinya terhadap objek. Responden pada dasarnya memiliki pendapatan yang tinggi, hal ini disebabkan kebutuhan sehari-hari sudah tercukupi oleh hasil dari penjualan susu. Sedangkan pendapatan dari usahatani atau pekerjaan lain dapat ditabung untuk kebutuhan mendesak lainnya.

5) Pengaruh Motivasi $\left(\mathrm{X}_{5}\right)$ terhadap Persepsi Anggota Terhadap Unit Usaha Susu KUD Cepogo

Berdasarkan tabel 7 nilai koefisien regresi sebesar 2,568. Koefisien bernilai positif artinya hubungan variabel motivasi terhadap persepsi anggota terhadap unit usaha susu KUD Cepogo berbanding lurus. Artinya semakin tinggi motivasi maka sejalan dengan meningkatnya persepsi anggota terhadap unit usaha susu KUD Cepogo. Secara parsial motivasi berpengaruh terhadap persepsi anggota terhadap unit usaha susu KUD Cepogo. Hasil olah data menunjukkan bahwa nilai sig pada variabel motivasi $\left(\mathrm{X}_{5}\right)$ sebesar 0,000 sehingga sig. $\leq \alpha$ atau $0,000<0,05$. Maka $\mathrm{H}_{1}$ diterima dan $\mathrm{H}_{0}$ ditolak. Artinya motivasi secara parsial mempunyai pengaruh yang signifikan terhadap persepsi anggota dengan tingkat kepercayaan 95\%. Hal ini menunjukkan motivasi mampu memberikan pengaruh terhadap persepsi anggota terhadap unit usaha susu KUD Cepogo.

Pengaruh yang signifikan antara motivasi dengan persepsi sejalan dengan pernyataan Mulyana (2004) persepsi dipengaruhi oleh faktor-faktor sosial budaya dan faktor-faktor psikologis. Faktor-faktor psikologis seperti kemauan, keinginan, motivasi, pengharapan, dan sebagainya. Responden memiliki dorongan dari diri sendiri untuk usaha ternak sapi perah dan bergabung menjadi anggota unit usaha susu KUD. Responden termotivasi karena hasil dari usaha ternak sapi perah dapat meningkatkan perekonomian keluarga. Motivasi lain responden bergabung menjadi anggota KUD adalah karena pelayanannya yang sangat membantu anggota untuk meningkatkan produksi susu dan pemasaran susu, sehingga kesejahteraan responden meningkat.

Tabel 8

Model Summary

\begin{tabular}{lll}
\hline Model & $R$ & $R$ Square \\
\hline 1 & 0,799 & 0,639 \\
\hline
\end{tabular}

Sumber: Analisis Data Primer, (2020)

Uji kelayakan model menggunakan analisis koefisien determinasi $\left(\mathrm{R}^{2}\right)$ pada intinya mengukur seberapa jauh kemampuan sebuah model menerangkan variasi variabel dependen. Nilai koefisien determinasi adalah nol dan satu. Nilai $\mathrm{R}^{2}$ yang kecil berarti kemampuan variabel-variabel independen dalam menjelaskan variabel dependen sangat terbatas. Nilai yang mendekati satu berarti variabel-variabel independen memberikan hampir semua informasi yang diberikan untuk memprediksi variasi variabel dependen (Ghozali, 2011). Berdasarkan tabel 8 hasil dari uji Koefisien Determinasi $\left(\mathrm{R}^{2}\right)$ menunjukkan 0,639 atau sebesar 63,9 \%. Hasil perhitungan ini berarti bahwa kemampuan variabel independen dalam menerangkan variabel dependen sebesar 
$63,9 \%$, sedangkan sisanya sebesar 36,1\% diterangkan oleh faktor-faktor lain di luar model regresi yang dianalisis.

\section{Kesimpulan}

Berdasarkan hasil penelitian dan pembahasan, maka dapat disimpulkan bahwa persepsi anggota terhadap unit usaha susu KUD Cepogo dalam Kategori Baik. Faktor-faktor pembentuk persepsi yaitu pendidikan formal, pendidikan non formal, pengalaman, pendapatan, dan motivasi. Pengaruh faktor-faktor pembentuk persepsi terhadap persepsi anggota terhadap unit usaha susu KUD Cepogo secara simultan berpengaruh signifikan. Secara parsial faktor pendidikan formal dan pendidikan non formal tidak berpengaruh signifikan terhadap persepsi anggota terhadap unit usaha susu KUD Cepogo. Faktor pengalaman, pendapatan, dan motivasi berpengaruh signifikan terhadap persepsi anggota terhadap unit usaha susu KUD Cepogo. Berdasarkan hasil penelitian, maka saran yang dapat diberikan adalah berdasaekan pengalaman, responden diharapkan lebih meningkatkan kecermatannya dalam mengambil suatu keputusan agar dapat terhindar dari suatu kesalahan yang pernah dialami. Berdasarkan pendapatan, responden diharapakan lebih dapat memanfaatkan pendapatan yang dimiliki untuk mengembangkan usaha ternak sapi perah agar hasil produksi dan pendapatan terus meningkat. Berdasarkan motivasi, responden diharapkan dapat lebih semangat dalam mengembangkan usaha ternak sapi perah dan mengikuti kegiatan unit usaha susu KUD Cepogo.

\section{Ucapan Terimakasih}

Penulis mengucapkan terima kasih kepada seluruh pihak yang telah membantu dalam menyelesaikan penelitian ini.

\section{Daftar Pustaka}

Aini A. N. (2015). Pengaruh Keanggotaan Koperasi Terhadap Pendapatan Peternak Sapi Perah di Kud Cepogo, Kecamatan Cepogo, Kabupaten Boyolali. Surakarta: UNS.

Badan Pusat Statistik. (2019). Populasi Sapi Perah di Provinsi Jawa Tenga di Provinsi Jawa Tengah 2019. Badan Pusat Statistik Jawa Tengah: CV. Surya Lestari.

Ghozali I. (2011). Aplikasi Analisis Multivariate dengan program SPSS. Semarang: Badan Penerbit UNDIP.

Luthfi. (2018). Persepsi petani terhadap program dem area budidaa tanaman sehat padi (studi kasus di Kecamatan Polokarto kabupaten Sukoharjo). Surakarta: UNS.

Mulyana D. (2004). Ilmu Komunikasi: Suatu Pegantar. Biomass Chem Eng.

Nadhiroh, H. (2019). Peran Kud Tani Wilis dalam Pengembangan Ekonomi Masyarakat Desa Nyawangan Kec Sendang Kab Tulungangug. Pustaka Unpad.

Rakhmat J. (2011). Psikologi Komunikasi. Bandung: Remaja Rosdakarya.

Santosa D \& Putri I. Y. (2018). Peran Koperasi Unit Desa dalam Kegiatan Usaha Masyarakat. Firm Journal of Management Studies.

Sutarto W. (2016). Persepsi Petani terhadap Pengembangan System of Rice Intensification (SRI) di Kecamatan Moga Kabupaten Pemalang. Jurnal Ilmiah Mahasiswa Agribisnis UNS, 4(3), 476-485. 
Undang-Undang Republik Indonesia Nomor 25 Tahun 1992 Tentang Perkoperasian.

Wahyudi, T. (2008). Pengaruh Motivasi, Jenis Kelamin, dan Kepuasan Kerja Terahadap Kinerja Akuntan Pada Perusahaan Manufaktur di Kota Surakarta. Surakarta: UMS.

Walgito B. (2010). Pengantar Psikologi sosial. Yogyakarta: Andi Ofset.

Zamzam Q. (2016). Persepsi Masyarakat terhadap Keberadaan Koperasi Mekar Sari dalam Meningkatkan Kesejahteraan Anggotanya. Pustaka IPB. 